OPEN ACCESS

Edited by:

Fulai Liu,

University of Copenhagen, Denmark

Reviewed by:

Mathias Neumann Andersen,

Aarhus University, Denmark

Deliang Kong,

Henan Agricultural University, China

${ }^{*}$ Correspondence:

Yu-Guo Liu

liuyuguo@caf.ac.cn

Shuang-Xi Zhou

shuangxi.zhou@plantandfood.co.nz

†These authors have contributed equally to this work

Specialty section: This article was submitted to Plant Physiology, a section of the journal

Frontiers in Plant Science

Received: 22 September 2019

Accepted: 16 March 2020

Published: 24 April 2020

Citation:

Ye Z-P, Ling Y, Yu Q, Duan H-L, Kang $H-J$, Huang G-M, Duan S-H, Chen X-M, Liu Y-G and Zhou S-X (2020) Quantifying Light Response of Leaf-Scale Water-Use Efficiency and Its Interrelationships With Photosynthesis and Stomatal Conductance in $C_{3}$ and $C_{4}$ Species.

Front. Plant Sci. 11:374.

doi: 10.3389/fpls.2020.00374

\section{Quantifying Light Response of Leaf-Scale Water-Use Efficiency and Its Interrelationships With Photosynthesis and Stomatal Conductance in $\mathrm{C}_{3}$ and $\mathrm{C}_{4}$ Species}

\author{
Zi-Piao Ye ${ }^{1 \dagger}$, Yu Ling ${ }^{2 \dagger}$, Qiang Yu ${ }^{3,4,5}$, Hong-Lang Duan ${ }^{6}$, Hua-Jing Kang ${ }^{7}$, \\ Guo-Min Huang ${ }^{6}$, Shi-Hua Duan ${ }^{8}$, Xian-Mao Chen ${ }^{9}$, Yu-Guo Liu ${ }^{10 *}$ and \\ Shuang-Xi Zhou'11*
}

${ }^{1}$ Maths \& Physics College, Jinggangshan University, Ji'an, China, ${ }^{2}$ College of Agricultural Sciences, Guangdong Ocean University, Zhanjiang, China, ${ }^{3}$ State Key Laboratory of Soil Erosion and Dryland Farming on the Loess Plateau, Northwest A\&F University, Yangling, China, ${ }^{4}$ School of Life Sciences, University of Technology Sydney, Ultimo, NSW, Australia, ${ }^{5}$ College of Resources and Environment, University of Chinese Academy of Science, Beijing, China, ${ }^{6}$ Jiangxi Provincial Key Laboratory for Restoration of Degraded Ecosystems and Watershed Ecohydrology, Nanchang Institute of Technology, Nanchang, China, ${ }^{7}$ Department of Landscape Architecture, Wenzhou Vocational College of Science \& Technology, Wenzhou, China, ${ }^{8}$ School of Life Sciences, Jinggangshan University, Ji'an, China, ${ }^{9}$ Soil Fertilizer and Environmental Resources Institute, Jiangxi Academy of Agricultural Sciences, Nanchang, China, ${ }^{10}$ Institute of Desertification Studies, Chinese Academy of Forestry, Beijing, China, " The New Zealand Institute for Plant and Food Research Limited, Havelock North, New Zealand

Light intensity $(I)$ is the most dynamic and significant environmental variable affecting photosynthesis $\left(A_{n}\right)$, stomatal conductance $\left(g_{s}\right)$, transpiration $\left(T_{r}\right)$, and water-use efficiency (WUE). Currently, studies characterizing leaf-scale WUE-l responses are rare and key questions have not been answered. In particular, (1) What shape does the response function take? (2) Are there maximum intrinsic $\left(W U E_{i} ; W U E_{i-\max }\right)$ and instantaneous WUE (WUE $E_{\text {inst }} ; W_{\text {U }}$ inst-max) at the corresponding saturation irradiances $\left(I_{i-s a t}\right.$ and $\left.I_{\text {inst-sat }}\right)$ ? This study developed $W E_{i}-I$ and $W E_{\text {inst }}-l$ models sharing the same non-asymptotic function with previously published $A_{n}-l$ and $g_{s}-1$ models. Observation-modeling intercomparison was conducted for field-grown plants of soybean $\left(\mathrm{C}_{3}\right)$ and grain amaranth $\left(\mathrm{C}_{4}\right)$ to assess the robustness of our models versus the non-rectangular hyperbola models ( $\mathrm{NH}$ models). Both types of models can reproduce WUE-I curves well over light-limited range. However, at light-saturated range, $\mathrm{NH}$ models overestimated $\mathrm{WUE}_{\mathrm{i}-\max }$ and $\mathrm{WUE}_{\text {inst-max }}$ and cannot return $I_{\mathrm{i} \text {-sat }}$ and $l_{\text {inst-sat }}$ due to its asymptotic function. Moreover, $\mathrm{NH}$ models cannot describe the downregulation of WUE induced by high light, on which our models described well. The results showed that $W U E_{i}$ and $W U E_{\text {inst }}$ increased rapidly within low range of $I$, driven by uncoupled photosynthesis and stomatal responsiveness. Initial response rapidity of WUE $E_{i}$ was higher than WUE $E_{i n s t}$ because the greatest increase of $A_{n}$ and $T_{r}$ occurred at low $g_{\mathrm{s}} . \mathrm{C}_{4}$ species showed higher $W U E_{i-\max }$ and $W U E_{\text {inst-max }}$ than $\mathrm{C}_{3}$ species - at similar $I_{i}$-sat and $l_{\text {inst-sat. }}$. Our intercomparison highlighted larger discrepancy between $W U E_{i}-I$ and $W_{U} E_{i n s t}-/$ responses in $C_{3}$ than $C_{4}$ species, quantitatively characterizing an 
important advantage of $\mathrm{C}_{4}$ photosynthetic pathway-higher $A_{n}$ gain but lower $T_{r}$ cost per unit of $g_{s}$ change. Our models can accurately return the wealth of key quantities defining species-specific WUE-l responses-besides $A_{n}-l$ and $g_{s}-l$ responses. The key advantage is its robustness in characterizing these entangled responses over a wide I range from light-limited to light-inhibitory light intensities, through adopting the same analytical framework and the explicit and consistent definitions on these responses. Our models are of significance for physiologists and modelers - and also for breeders screening for genotypes concurrently achieving maximized photosynthesis and optimized WUE.

Keywords: irradiance, leaf gas exchange, light response curve, maximum water use efficiency, model, plant functional type (PFT), saturation light intensity, transpiration

\section{INTRODUCTION}

Stomata control the balance between carbon flux driven by photosynthesis and water flux dominated by transpiration, which is characterized by water-use efficiency (WUE) at various scales (Sinclair et al., 1984; Gilbert et al., 2011; Eamus et al., 2016; Medlyn et al., 2017). WUE can thus indicate the natural selection on the balance between these fluxes (Hetherington and Woodward, 2003). Characterizing the environmental impacts on WUE among plant species and/or plant function types can advance our knowledge on differential plant adaptation strategies, and improve our prediction on consequences of environmental challenges (Avola et al., 2008; Egea et al., 2011; Zhou et al., 2014, 2016; De Kauwe et al., 2015; Köhler et al., 2016; Ahrar et al., 2017). For instance, plant species with the highest WUE would show the greatest fitness in dry habitats (Dudley, 1996; Zhou et al., 2019). WUE is also an important metric in crop breeding and genotype selection, especially for irrigated crops whose water use significantly affects crop productivity and profitability (Duursma et al., 2013; Flexas et al., 2013; Bota et al., 2016; Webster et al., 2016).

WUE can be estimated using different techniques, based on observations of leaf gas exchange, stable isotope discrimination, and eddy covariance fluxes (Medlyn et al., 2017). Among these techniques, WUE is most commonly estimated by measuring leaf gas exchange, facilitated by portable photosynthesis system allowing simultaneous measurement of leaf-scale carbon and water fluxes (Medrano et al., 2015). WUE derived from leaf gas exchange measurement is usually defined as the ratio of net $\mathrm{CO}_{2}$ assimilation rate $\left(A_{\mathrm{n}}\right)$ to stomatal conductance for water vapor $\left(g_{\mathrm{s}}\right)$-intrinsic water-use efficiency (WUE $\mathrm{W}_{\mathrm{i}}$; von Caemmerer and Farquhar, 1981), or the ratio of $A_{\mathrm{n}}$ to transpiration rate $\left(T_{\mathrm{r}}\right)-$

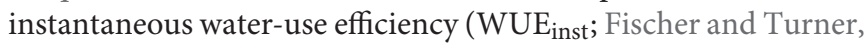
1978) (see Table 1 for a summary of parameters and units). WUE $_{\mathrm{i}}$ can be used to compare photosynthetic characteristics independently of evaporative demand (Linares and Camarero, 2012). WUE $E_{\text {inst }}$ is a key determinant of whole-plant WUE as it summarizes plant dry mass production per unit of water loss (Sinclair et al., 1984; Duursma et al., 2013; but see Medrano et al., 2015 for constraints). $\mathrm{WUE}_{\mathrm{i}}$ and $\mathrm{WUE}_{\mathrm{inst}}$ have been widely used as an index of plant and vegetation performances in response to various environmental changes, such as changed water or light availabilities, vapor pressure deficit (VPD), temperature and $\mathrm{CO}_{2}$ concentration (Aranda et al., 2007; Avola et al., 2008; Linares and Camarero, 2012; Duursma et al., 2013; Bota et al., 2016).

Light is often viewed as the most significant environmental variable affecting photosynthesis, stomatal behavior and WUE (Knapp and Smith, 1987; Aranda et al., 2007; McAusland et al., 2016). Plants in most ecosystems experience rapid short-term variability in light resource (Smith et al., 1989), which can cause continual transition of $A_{\mathrm{n}}, g_{\mathrm{s}}, T_{\mathrm{r}}, \mathrm{WUE}_{\mathrm{i}}$, and $\mathrm{WUE}_{\text {inst }}$ throughout the growing season (Knapp and Smith, 1990; Knapp, 1993). However, studies characterizing the light response of WUE are rare (McAusland et al., 2016). It is largely unknown whether there is a maximum $\mathrm{WUE}_{\mathrm{i}}$ or $\mathrm{WUE}_{\text {inst }}$-and the corresponding saturation irradiance-for plants under dynamic irradiance conditions, or how plant species or plant function types (PFTs) would differ in their light responses of $\mathrm{WUE}_{\mathrm{i}}$ and $\mathrm{WUE}_{\text {inst }}$.

Characterization of the interrelationships among light responses of $A_{\mathrm{n}}, g_{\mathrm{s}}, T_{\mathrm{r}}, \mathrm{WUE}_{\mathrm{i}}$ and $\mathrm{WUE}_{\text {inst }}$ - which can be simultaneously measured-will be fundamental to the scaling-up modeling of WUE-I responses at the whole-plant and ecosystem scale. The foremost step toward this direction calls for a robust model, with which (1) the $\mathrm{WUE}_{\mathrm{i}}$ and $\mathrm{WUE}_{\text {inst }}$ responses to a gradient of irradiance intensity $(I)$ levels (WUE $\mathrm{W}_{\mathrm{i}}-I$ and $\mathrm{WUE}_{\mathrm{inst}}-I$ response curve, respectively) can be characterized, and (2) the key quantities defining the response curves-such as the initial slope of the response curve, the maximum WUE and the corresponding saturation irradiance-can be quantified. Ideally, the model can accurately represent the differential $\mathrm{WUE}_{\mathrm{i}}$ and $\mathrm{WUE}_{\text {inst }}$ responses among plant species or PFTs, such as that reported between $\mathrm{C}_{3}$ and $\mathrm{C}_{4}$ species with contrasting light responses of photosynthesis, stomatal functioning, and WUE (Pearcy and Ehleringer, 1984; Knapp, 1993). For a given $A_{\mathrm{n}}, g_{\mathrm{s}}$ and $T_{\mathrm{r}}$ are higher in $\mathrm{C}_{3}$ than $\mathrm{C}_{4}$ plants, leading to higher $\mathrm{WUE}_{\mathrm{i}}$ and $\mathrm{WUE}_{\text {inst }}$ in $\mathrm{C}_{4}$ plants, which has higher utilization efficiency of $\mathrm{CO}_{2}$ at relatively lower intercellular $\mathrm{CO}_{2}$ concentration (Pearcy and Ehleringer, 1984). The objectives of this study were to develop a leaf-scale WUE-I model and assess the model performance against experimental field observations of $\mathrm{C}_{3}$ and $\mathrm{C}_{4}$ species in order to answer key questions of how best to model the light response of $\mathrm{WUE}_{\mathrm{i}}$ and $\mathrm{WUE}_{\mathrm{inst}}$. In particular: (1) What shape does the leaf-scale WUE-I response function 


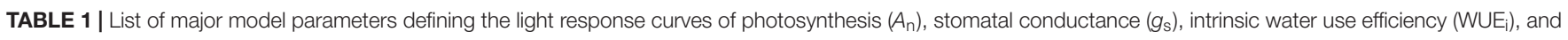
instantaneous water use efficiency (WUE $E_{\text {inst }}$ ).

\begin{tabular}{|c|c|c|}
\hline Symbol & Definition & Unit \\
\hline$A_{\mathrm{n}}$ & Net photosynthetic rate & $\mu \mathrm{mol} \mathrm{CO} 2 \mathrm{~m}^{-2} \mathrm{~s}^{-1}$ \\
\hline$A_{\text {nmax }}$ & Maximum net photosynthetic rate & $\mu \mathrm{mol} \mathrm{CO} 2 \mathrm{~m}^{-2} \mathrm{~s}^{-1}$ \\
\hline$g_{\mathrm{s}}$ & Stomatal conductance & $\mathrm{mol} \mathrm{H}_{2} \mathrm{O} \mathrm{m} \mathrm{m}^{-2} \mathrm{~s}^{-1}$ \\
\hline$g_{\mathrm{s}-\max }$ & Maximum stomatal conductance & $\mathrm{mol} \mathrm{H}_{2} \mathrm{O} \mathrm{m} \mathrm{m}^{-2} \mathrm{~s}^{-1}$ \\
\hline 1 & Light intensity & $\mu \mathrm{mol}$ photons $\mathrm{m}^{-2} \mathrm{~s}^{-1}$ \\
\hline Isat & Saturation light intensity corresponding to maximum net photosynthetic rate & $\mu \mathrm{mol}$ photons $\mathrm{m}^{-2} \mathrm{~s}^{-1}$ \\
\hline Ig-sat & Saturation light intensity corresponding to maximum stomatal conductance & $\mu \mathrm{mol}$ photons $\mathrm{m}^{-2} \mathrm{~s}^{-1}$ \\
\hline li-sat & Saturation light intensity corresponding to maximum intrinsic water-use efficiency & $\mu \mathrm{mol}$ photons $\mathrm{m}^{-2} \mathrm{~s}^{-1}$ \\
\hline linst-sat & Saturation light intensity corresponding to maximum instantaneous water-use efficiency & $\mu \mathrm{mol}$ photons $\mathrm{m}^{-2} \mathrm{~s}^{-1}$ \\
\hline$R_{\mathrm{d}}$ & Mitochondrial $\mathrm{CO}_{2}$ release in the dark & $\mu \mathrm{mol} \mathrm{CO} \mathrm{CO}^{-2} \mathrm{~s}^{-1}$ \\
\hline$T_{r}$ & Transpiration rate & $\mathrm{mmol} \mathrm{H} \mathrm{O} \mathrm{m}^{-2} \mathrm{~s}^{-1}$ \\
\hline WUE & Intrinsic water-use efficiency & $\mu \mathrm{mol} \mathrm{CO} \mathrm{mol}^{-1} \mathrm{H}_{2} \mathrm{O}$ \\
\hline WUE $_{\mathrm{i}-\max }$ & Maximum intrinsic water-use efficiency & $\mu \mathrm{mol} \mathrm{CO} \mathrm{mol}^{-1} \mathrm{H}_{2} \mathrm{O}$ \\
\hline WUE $E_{\text {inst }}$ & Instantaneous water-use efficiency & $\mu \mathrm{mol} \mathrm{CO} 2 \mathrm{mmol}^{-1} \mathrm{H}_{2} \mathrm{O}$ \\
\hline WUE $_{\text {inst-max }}$ & Maximum instantaneous water-use efficiency & $\mu \mathrm{mol} \mathrm{CO} 2 \mathrm{mmol}^{-1} \mathrm{H}_{2} \mathrm{O}$ \\
\hline$\alpha, \alpha_{0}, \alpha_{1}, \alpha_{2}$ & Initial slope of light response curve of $A_{n}, g_{s}, W U E_{i}$ and $W U E_{i n s t}$ & $\mathrm{mmol} \mathrm{H} \mathrm{O} \mathrm{m}^{-2} \mathrm{~s}^{-1}$ \\
\hline$\beta, \beta_{0}, \beta_{1}, \beta_{2}$ & Inhibitor coefficient of light response curve of $A_{n}, g_{s}, W U E_{i}$ and $W U E_{i n s t}$ & $\mathrm{~m}^{2} \mathrm{~s} \mu \mathrm{mol}^{-1}$ photons \\
\hline$\gamma, \gamma_{0}, \gamma_{1}, \gamma_{2}$ & Saturation coefficient of light response curve of $A_{n}, g_{s}, W U E_{i}$ and $W U E_{i n s t}$ & $\mathrm{~m}^{2} \mathrm{~s} \mu \mathrm{mol}^{-1}$ photons \\
\hline$K_{\mathrm{i}}$ & Residual intrinsic water-use efficiency & $\mu \mathrm{mol} \mathrm{CO} \mathrm{Col}^{-1} \mathrm{H}_{2} \mathrm{O}$ \\
\hline$K_{\text {inst }}$ & Residual instantaneous water-use efficiency & $\mu \mathrm{mol} \mathrm{CO} 2 \mathrm{mmol}^{-1} \mathrm{H}_{2} \mathrm{O}$ \\
\hline
\end{tabular}

take? Is there a maximum $\mathrm{WUE}_{\mathrm{i}}$ and/or $\mathrm{WUE}_{\text {inst }}$-and the corresponding saturation irradiances for plants under dynamic irradiance conditions? (2) Can the model well represent the differential $\mathrm{WUE}_{\mathrm{i}}-I$ and/or $\mathrm{WUE}_{\mathrm{inst}}-I$ response characteristics between $\mathrm{C}_{3}$ and $\mathrm{C}_{4}$ species? By integrating the published $A_{\mathrm{n}}-I$ (Ye, 2007; Ye et al., 2013) and $g_{\mathrm{s}}-I$ (Ye and Yu, 2008) response function, we developed an explicit WUE-I modeling framework and hypothesized that the species-specific light response curves of $W_{U E}$ and $W E_{i n s t}$ can be quantitatively characterized using the same non-asymptotic function. The hypothesis was tested using an observation-modeling intercomparison on $\mathrm{WUE}_{\mathrm{i}}-I$ and $\mathrm{WUE}_{\mathrm{inst}}-I$ responses for field-grown $\mathrm{C}_{3}$ [soybean (Glycine max L.)] and $\mathrm{C}_{4}$ species [grain amaranth (Amaranthus hypochondriacus L.)] under high $I$ condition in the growing season. Model performance against that of the non-rectangular hyperbola model was also evaluated.

\section{MATERIALS AND METHODS}

\section{Analytical Models}

A non-asymptotic model has been previously developed and tested to well characterize the light response of photosynthesis (Ye, 2007; Ye et al., 2013), with its simplified form as follows:

$$
A_{\mathrm{n}}=\alpha \frac{1-\beta I}{1+\gamma I} I-R_{\mathrm{d}}
$$

where $\alpha$ is the initial slope of light response curve of photosynthesis, $I$ is the irradiance, and $\beta$ and $\gamma$ are the photoinhibition coefficient and saturation coefficient, respectively, and $R_{\mathrm{d}}$ is the dark respiratory rate. The key model parameters are listed in Table 1.
The saturation irradiance $\left(I_{\text {sat }}\right)$ corresponding to the lightsaturated photosynthetic rate $\left(A_{\mathrm{n} \max }\right)$ can be calculated as follows:

$$
\begin{gathered}
I_{\text {sat }}=\frac{\sqrt{(\beta+\gamma) / \beta}-1}{\gamma} \\
A_{\text {nmax }}=\alpha\left(\frac{\sqrt{\beta+\gamma}-\sqrt{\beta}}{\gamma}\right)^{2}-R_{\mathrm{d}}
\end{gathered}
$$

Eq. 1 has been widely used to characterize photosynthetic light response curves of various plant species under different environmental conditions, highlighting its better performance than that of rectangular (Baly, 1935) and non-rectangular hyperbolic models (Thornley, 1976; Wargent et al., 2011; Xu et al., 2012a,b; Song et al., 2015; Chen et al., 2016). The rectangular and the non-rectangular hyperbolic models have been reported to overestimate $A_{n \max }$ (dos Santos et al., 2013), and cannot quantify $I_{\text {sat }}$ (Gomes et al., 2006; dos Santos et al., 2013; Song et al., 2015; Chen et al., 2016).

Meanwhile, a model of the same non-asymptotic form as Eq. 1 has been developed and tested to well characterize the light response of stomatal conductance (Ye and Yu, 2008), as follows:

$$
g_{s}=\alpha_{0} \frac{1-\beta_{0} I}{1+\gamma_{0} I} I+g_{s 0}
$$

where $\alpha_{0}$ is the initial slope of light response curve of stomatal conductance, $g_{s 0}$ is the residual stomatal conductance, and $\beta_{0}$ and $\gamma_{0}$ are two coefficients that are independent of $I$ ( $\mathrm{Ye}$ and $\mathrm{Yu}, 2008$ ). Most existing stomatal conductance models cannot quantify the $g_{s-\max }$ or the corresponding $I_{\text {g-sat }}$ under changing irradiance conditions (Dewar, 2002; Buckley et al., 2003; Buckley and Mott, 2013; Flexas et al., 2013). 
The $g_{\mathrm{s}}-I$ model developed by $\mathrm{Ye}$ and $\mathrm{Yu}$ (2008) can well characterize the $g_{\mathrm{s}}-I$ response, from which key parameters defining the $g_{\mathrm{s}}-I$ response-such as $g_{s-\max }$ and $I_{\mathrm{g}-\text { sat }}-$ can be easily obtained.

The saturation irradiance $\left(I_{\mathrm{g}-\text { sat }}\right)$ corresponding to the lightsaturated stomatal conductance $\left(g_{s-\max }\right)$ can be calculated as follows:

$$
\begin{gathered}
I_{\mathrm{g}-\mathrm{sat}}=\frac{\sqrt{\left(\beta_{0}+\gamma_{0}\right) / \beta_{0}}-1}{\gamma_{0}} \\
g_{\mathrm{smax}}=\alpha_{0}\left(\frac{\sqrt{\beta_{0}+\gamma_{0}}-\sqrt{\beta_{0}}}{\gamma_{0}}\right)^{2}+g_{\mathrm{s} 0}
\end{gathered}
$$

Here, we hypothesize that the light response of $\mathrm{WUE}_{\mathrm{i}}$ can be characterized using the same non-asymptotic form as that of the $A_{\mathrm{n}}-I$ (Eq. 1) and $g_{\mathrm{s}}-I$ (Eq. 4) response functions, as follows:

$$
\mathrm{WUE}_{\mathrm{i}}=\alpha_{1} \frac{1-\beta_{1} I}{1+\gamma_{1} I} I-K_{i}
$$

where $\alpha_{1}$ represents the initial slope of light response curve of $\mathrm{WUE}_{\mathrm{i}}, \beta_{1}$, and $\gamma_{1}$ are coefficients that are independent of $I$, and $K_{\mathrm{i}}$ is the residual intrinsic water-use efficiency. The saturation irradiance $\left(I_{\mathrm{i}-\mathrm{sat}}\right)$ corresponding to the maximum $\mathrm{WUE}_{\mathrm{i}}\left(\mathrm{WUE}_{\mathrm{i}-\text { max }}\right)$ can be calculated as follows:

$$
\begin{gathered}
I_{\mathrm{i}-\mathrm{sat}}=\frac{\sqrt{\left(\beta_{1}+\gamma_{1}\right) / \beta_{1}}-1}{\gamma_{1}} \\
\mathrm{WUE}_{\mathrm{i}-\max }=\alpha_{1}\left(\frac{\sqrt{\beta_{1}+\gamma_{1}}-\sqrt{\beta_{1}}}{\gamma_{1}}\right)^{2}-K_{i}
\end{gathered}
$$

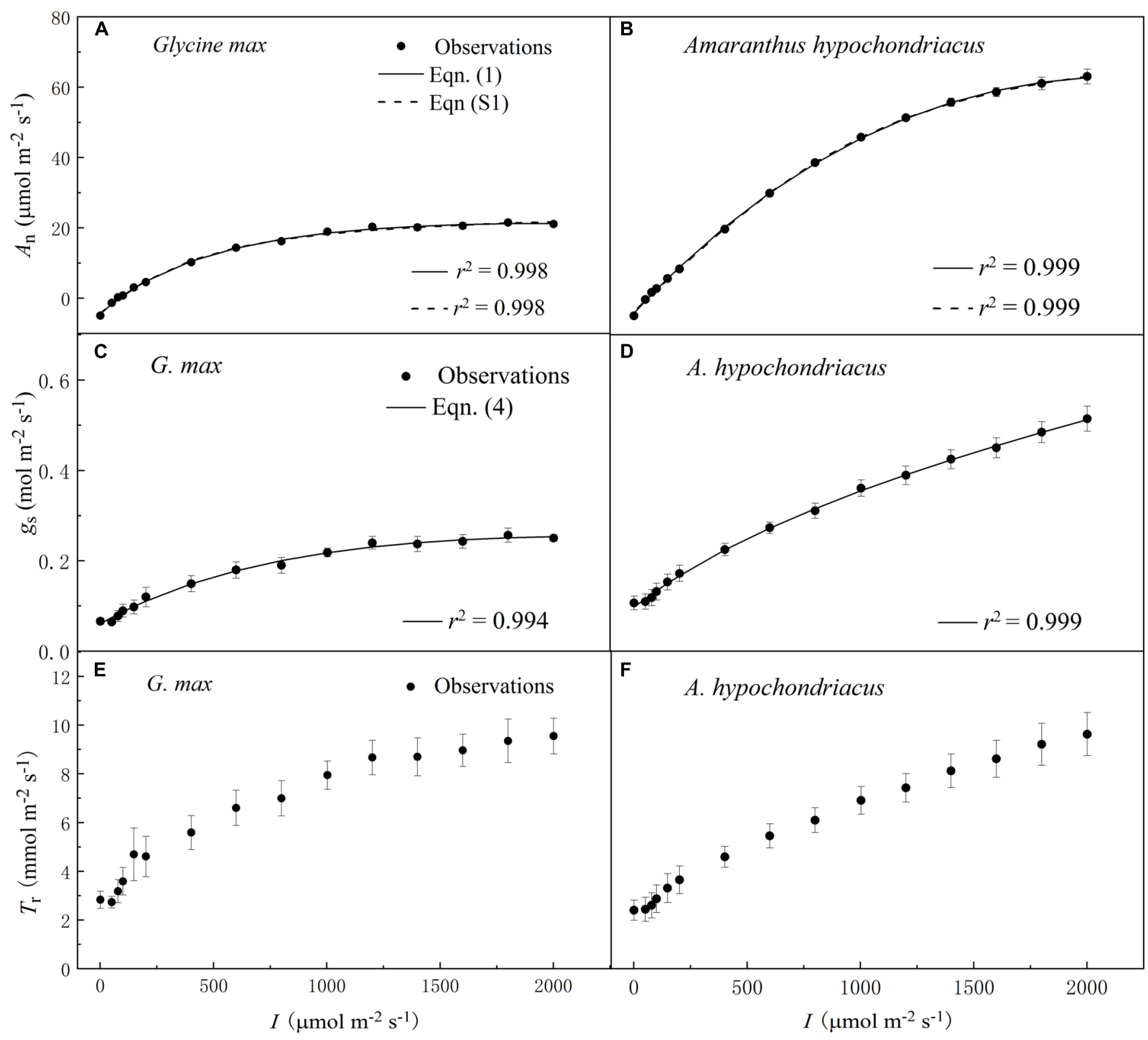

FIGURE 1 | Irradiance $(h)$ responses of net photosynthetic rate $\left(A_{n}\right)(\mathbf{A}, \mathbf{B})$, stomatal conductance $\left(g_{\mathrm{s}}\right)(\mathbf{C}, \mathbf{D})$ and transpiration rate $\left(T_{r}\right)(\mathbf{E}, \mathbf{F})$ for $\mathrm{C}_{3}[$ soybean $(G / y c i n e$ max)] and $\mathrm{C}_{4}$ species [grain amaranth (Amaranthus hypochondriacus)], respectively. In plots (A) and (B), solid lines were fitted using Eq. 1 and dashed lines were fitted using the non-rectangular hyperbola model (Eq. S1). In plots (C) and (D), solid lines were fitted using Eq. 4. Data are the mean \pm SE $(n=4)$. 
Since $g_{\mathrm{s}}$ controls leaf $T_{\mathrm{r}}$ at a given VPD (Duursma et al., 2013), we hypothesize that the light response of $\mathrm{WUE}_{\text {inst }}$ can also be characterized using the same non-asymptotic function as that of $\mathrm{WUE}_{\mathrm{i}}-I$ response function (Eq. 7), as follows:

$$
\mathrm{WUE}_{\text {inst }}=\alpha_{2} \frac{1-\beta_{2} I}{1+\gamma_{2} I} I-K_{\mathrm{inst}}
$$

where $\alpha_{2}$ represents the initial slope of light response curve of WUE $E_{\text {inst }}, \beta_{2}$ and $\gamma_{2}$ are coefficients that are independent of $I$, and $K_{\text {inst }}$ is the residual instantaneous water-use efficiency. The saturation irradiance $\left(I_{\text {inst-sat }}\right)$ corresponding to the maximum $\mathrm{WUE}_{\text {inst }}\left(\mathrm{WUE}_{\text {inst-max }}\right.$ ) can be calculated as follows:

$$
\begin{gathered}
I_{\text {inst }- \text { sat }}=\frac{\sqrt{\left(\beta_{2}+\gamma_{2}\right) / \beta_{2}}-1}{\gamma_{2}} \\
\text { WUE }_{\text {inst }-\max }=\alpha_{2}\left(\frac{\sqrt{\beta_{2}+\gamma_{2}}-\sqrt{\beta_{2}}}{\gamma_{2}}\right)^{2}-K_{\text {inst }}
\end{gathered}
$$

In this study, we tested if Eqs. 7 and 10 can well characterize the species-specific WUE-I response characteristics against modeloriented field observations and the simulations using the nonrectangular hyperbola model-in terms of the initial slope of light response curve of WUE ( $\alpha_{1}$ and $\alpha_{2}$, respectively), the maximum $\mathrm{WUE}_{\text {inst }}\left(\mathrm{WUE}_{\mathrm{i}}\right.$ and $\mathrm{WUE}_{\text {inst-max }}$, respectively), and the saturation irradiance $\left(I_{\mathrm{i}-\text { sat }}\right.$ and $I_{\text {inst-sat }}$, respectively).

\section{Study Site and Plant Material}

The field observations on one $\mathrm{C}_{3}$ species-soybean (Glycine max L.) and one $\mathrm{C}_{4}$ species-grain amaranth (A. hypochondriacus L.) were conducted at the Yucheng Comprehensive Experiment Station of the Chinese Academy of Sciences, located at the irrigation district of the Yellow River Basin in the North China Plain. This region is dominated by the warm-temperate semi-humid monsoon climate and is suitable for planting soybean and grain amaranth with high yields. This region has ample energy resource, and the light intensity in the growing season usually reaches $\sim 2000 \mu \mathrm{mol} \mathrm{m} \mathrm{m}^{-2} \mathrm{~s}^{-1}$ in sunny days. Soybean and grain amaranth were planted in field on May 3rd and June 15th 2012, respectively. All plants were kept under moist condition throughout the experiment.

\section{Light Response Curve Measurement}

The leaf gas exchange measurements were conducted after 45 days of growth in field-June 16th for soybean and July 29th for grain amaranth. Fully expanded sun-exposed leaves of four plants for each species were measured using a portable photosynthesis system (LI-6400, Li-Cor Inc., Lincoln, NE, United States). Before each measurement, the leaf was acclimated in the chamber to achieve stable gas exchange, with reference $\mathrm{CO}_{2}$ concentration maintained at $380 \mu \mathrm{mol}$ $\mathrm{CO}_{2} \mathrm{~mol}^{-1}$, irradiance intensity maintained at $2000 \mu \mathrm{mol}$ photon $\mathrm{m}^{-2} \mathrm{~s}^{-1}$, and leaf temperature maintained at $35^{\circ} \mathrm{C}$. After the leaf acclimated to the cuvette environment, the photosynthetic light response curve measurements were conducted with a descending gradient of irradiance intensity 


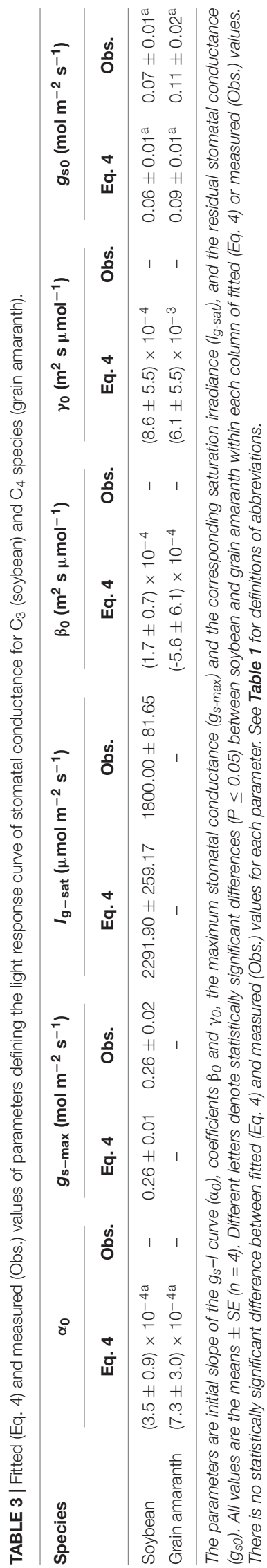

levels, as follows: 2000, 1800, 1600, 1400, 1200, 1000, 800, $600,400,200,150,100,80,50$, and $0 \mu \mathrm{mol} \mathrm{m} \mathrm{m}^{-2} \mathrm{~s}^{-1}$. At each irradiance level, leaf gas exchange was monitored to ensure reaching steady-state plateau before data-logging. VPD was kept stable during measurements (Supplementary Figure S1). The $A_{\mathrm{n}}-I, g_{\mathrm{s}}-I, \mathrm{WUE}_{\mathrm{i}}-I$, and $\mathrm{WUE}_{\mathrm{inst}}-I$ response curves were fitted by Eqs. $1,4,7$, and 10 , respectively. $I_{\text {sat }}, I_{\mathrm{g}-\text { sat }}$, $I_{\mathrm{i}-\text { sat }}$, and $I_{\text {inst-sat }}$ values were calculated following Eqs. 2, 5,8 , and 11 , respectively. $A_{n \max }, g_{\mathrm{s}-\max }, \mathrm{WUE}_{\mathrm{i}-\max }$, and $\mathrm{WUE}_{\text {inst-max }}$ values were calculated following Eqs. 3, 6, 9, and 12 , respectively.

\section{Data Analysis}

All statistical tests were performed using the statistical package SPSS 18.5 statistical software (SPSS, Chicago, IL, United States). The analysis of variance (ANOVA) was used to assess species effects. Paired-sample $t$ tests were conducted to test whether there were significant differences between fitted and measured values of quantitative traits $\left(\alpha, A_{\mathrm{nmax}}, I_{\mathrm{sat}}, \alpha_{0}, g_{\mathrm{s}-\max }, I_{\mathrm{g}-\mathrm{sat}}, \alpha_{1}\right.$, $\mathrm{WUE}_{\mathrm{i}-\max }, I_{\mathrm{i}-\text { sat }}, \alpha_{2}, \mathrm{WUE}_{\mathrm{inst}-\max }, I_{\text {inst-sat }}$, etc.). Goodness of fit of the mathematical model to experimental observations was assessed using the coefficient of determination $\left(r^{2}=1-S S E / S S T\right.$, where SST is the total sum of squares and SSE is the error sum of squares).

\section{RESULTS}

\section{Light Response Curves of $A_{\mathrm{n}}, g_{\mathrm{s}}$, and $T_{\mathrm{r}}$}

The increase of $I$ led to a rapid initial increase of $A_{\mathrm{n}}$ (Figures 1A,B), $g_{\mathrm{s}}$ (Figures 1C,D), and $T_{\mathrm{r}}$ (Figures 1E,F) for both $\mathrm{C}_{3}$ and $\mathrm{C}_{4}$ species. However, the initial increase rate of $A_{\mathrm{n}}$ was 100-fold higher than that of $g_{\mathrm{s}}$ for both species (Tables 2 and 3 ). The high coefficient of determination $\left(r^{2}\right)$ values indicated that the species-specific $A_{n}-I$ response curves fitted by Eq. 1 -and the $g_{\mathrm{s}}-I$ response curves fitted by Eq. $4-$ were highly representative of the observations for both species (Figure 1).

Soybean exhibited a single-peaked pattern for both $A_{n}-I$ and $g_{\mathrm{s}}-I$ responses, characterized by the increase of $A_{\mathrm{n}}$ and $g_{\mathrm{s}}$ with the increasing $I$ until reaching the $A_{n \max }$ and $g_{\mathrm{s}-\max }$ at the corresponding $I_{\text {sat }}$ and $I_{\mathrm{g}-\mathrm{sat}}$, respectively (Figures 1A,C and Tables 2 and 3). Compared with Eq. 1, the nonrectangular hyperbola model (Supplementary Eq. S1) showed similarly high $r^{2}$ value in simulating $A_{\mathrm{n}}-I$ response curves but significantly overestimated the $A_{\text {nmax }}$ (Figures 1A,B and Supplementary Table S1). Paired-sample $t$ tests showed there were no significant differences between the fitted values and the measured values of $A_{\text {nmax }}, I_{\text {sat }}, g_{\mathrm{s}-\max }$, and $I_{\mathrm{g}-\text { sat }}$ for soybean (Tables 2 and 3). Grain amaranth kept increasing its $A_{\mathrm{n}}$ and $g_{\mathrm{s}}$ within the range of irradiance intensity applied during measurements $\left(0-2000 \mu \mathrm{mol}\right.$ photon $\left.\mathrm{m}^{-2} \mathrm{~s}^{-1}\right)$, without showing an observational $A_{\text {nmax }}, I_{\text {sat }}, g_{s-\max }$, or $I_{\mathrm{g}-\mathrm{sat}}$ (Figures 1B,D and Tables 2 and 3). Grain amaranth showed relatively higher (not significant) initial increase rate of $g_{s}$, characterized by an initial slope of the light response curve of $g_{\mathrm{s}}\left(\alpha_{0}\right)$ (Figure 1 and Tables 2 and 3). 


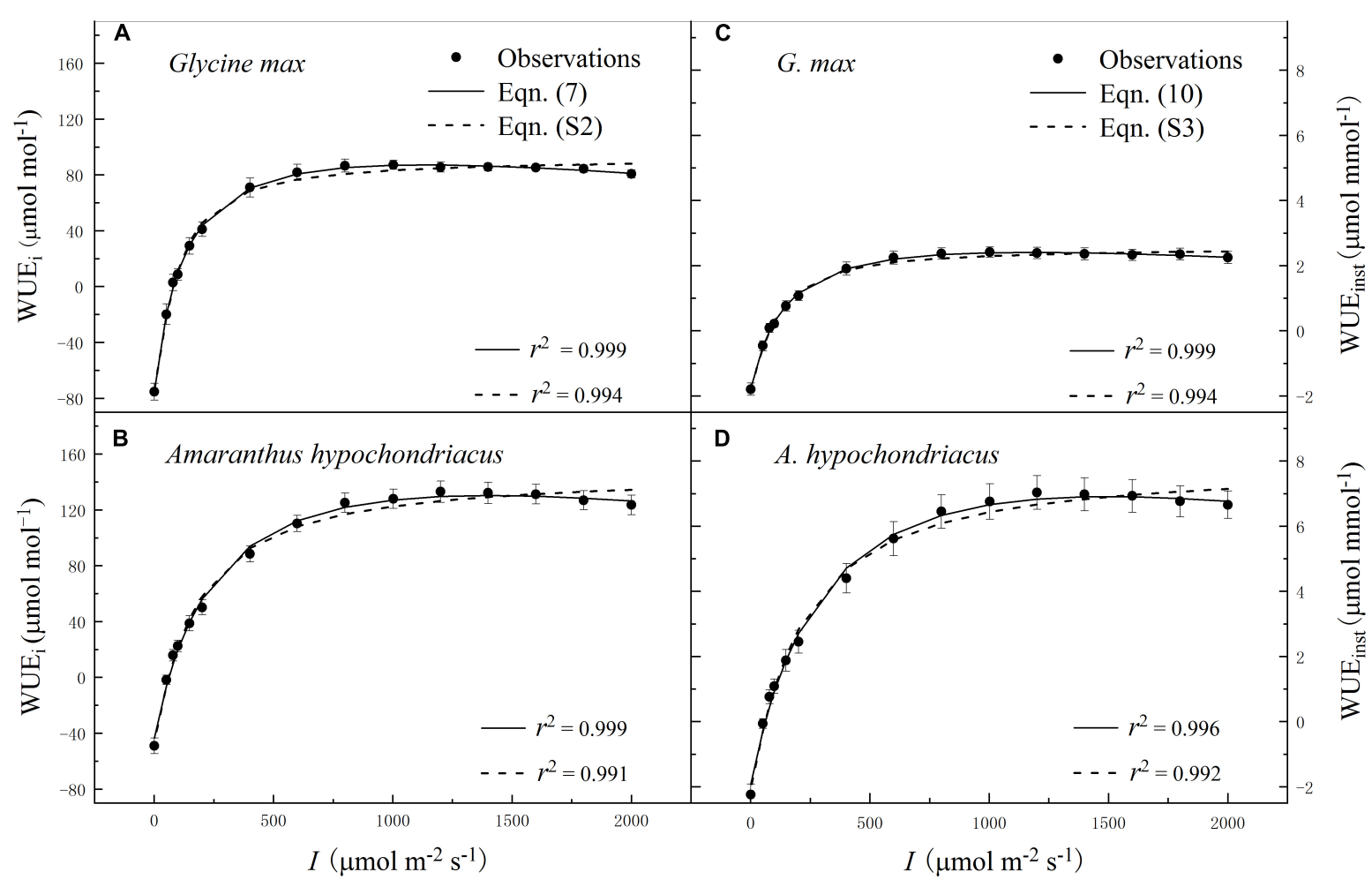

FIGURE 2 | Irradiance (I) response of intrinsic water-use efficiency $\left(W_{U} E_{i}\right)(\mathbf{A}, \mathbf{B})$ and instantaneous water-use efficiency $\left(W U E_{\text {inst }}\right)(\mathbf{C}, \mathbf{D})$ for $\mathrm{C}_{3}$ [soybean $(G / y c i n e$ max)] and $\mathrm{C}_{4}$ species [grain amaranth (Amaranthus hypochondriacus)], respectively. In plots $\mathbf{( A )}$ and (B), solid lines were fitted using Eq. 7 and dashed lines were fitted using the non-rectangular hyperbola model (Eq. S2). In plots (C) and (D), solid lines were fitted using Eq. 10 and dashed lines were fitted using the non-rectangular hyperbola model (Eq. S3). Data are the mean \pm SE $(n=4)$.

\section{Light Response Curves of $\mathrm{WUE}_{\mathrm{i}}$ and WUE $_{\text {inst }}$}

Within the low range of irradiance intensity, WUE $\mathrm{W}_{\mathrm{i}}$ and WUE $_{\text {inst }}$ of both species increased almost linearly with the increasing $I$. Both soybean and grain amaranth exhibited a singlepeaked $\mathrm{WUE}_{\mathrm{i}}-I$ and $\mathrm{WUE}_{\mathrm{inst}}-I$ response pattern, respectively. In particular, both species showed an increase of $W_{U E}$ and WUE $_{\text {inst }}$ with the increasing $I$ until reaching the speciesspecific $\mathrm{WUE}_{\mathrm{i}-\max }$ and $\mathrm{WUE}_{\mathrm{inst}-\max }$ at the corresponding species-specific saturation irradiance levels $\left(I_{\mathrm{i}-\text { sat }}\right.$ and $I_{\text {inst-sat }}$, respectively) (Figure 2 and Tables 4 and 5). However, soybean showed significantly lower observed and fitted $\mathrm{WUE}_{\mathrm{i}-\max }$ and WUE $_{\text {inst }-\max }(P \leq 0.05)$ than grain amaranth (Figure 2 and Tables 4 and 5). The two species showed no significant difference in $I_{\mathrm{i}-\text { sat }}, I_{\text {inst-sat }}$ or the initial increase rate of $\mathrm{WUE}_{\mathrm{i}}$ or $\mathrm{WUE}_{\text {inst }}-$ characterized by a maximal slope of the light response curves $\left(\alpha_{1}\right.$ and $\alpha_{2}$, respectively) (Figure 2 and Tables 4 and 5).

The high $r^{2}$ values indicated that $\mathrm{WUE}_{\mathrm{i}}-I$ response curves fitted by Eq. 7-and the $\mathrm{WUE}_{\text {inst }}-I$ response curves fitted by Eq. 10-were highly representative of the observations of both species (Figure $\mathbf{2}$ and Tables $\mathbf{4}$ and 5). There were no significant differences between fitted and observed values in $\mathrm{WUE}_{\mathrm{i}-\max }$, WUE $\mathrm{W}_{\text {inst-max }}, I_{\mathrm{i}-\text { sat }}, I_{\text {inst-sat }}, K_{\mathrm{i}}$, or $K_{\text {inst }}$ (Tables 4 and 5). Compared with Eqs. 7 and 10, the nonrectangular hyperbola model (Supplementary Eqs. S2 and S3, respectively) showed similarly high $r^{2}$ values but significantly overestimated $\mathrm{WUE}_{\mathrm{i}-\max }$ and $\mathrm{WUE}_{\text {inst-max }}$ for the two species (Supplementary Tables S2 and S3).

\section{Discussion}

Our $\mathrm{WUE}_{\mathrm{i}}-I$ and $\mathrm{WUE}_{\mathrm{inst}}-I$ models represented cultivarspecific response curves over a wide range of light intensities extremely well $\left(r^{2} \geq 0.996\right)$, including the decline of $\mathrm{WUE}_{\mathrm{i}}$ and $\mathrm{WUE}_{\text {inst }}$ beyond the saturation irradiances which the $\mathrm{NH}$ models cannot represent due to the asymptotic function. Our models can also return values for $\mathrm{WUE}_{\mathrm{i}-\max }$, WUE $\mathrm{W}_{\text {inst-max }}$, $I_{\mathrm{i}-\text { sat }}$, and $I_{\text {inst-sat }}$, which were in very close agreement with the measured values. The $\mathrm{NH}$ models cannot characterize the decline in $\mathrm{WUE}_{\mathrm{i}}$ and $\mathrm{WUE}_{\text {inst }}$ induced by high light, leading to overestimations of $\mathrm{WUE}_{\mathrm{i}-\max }$ and $\mathrm{WUE}_{\text {inst-max }}$ (Supplementary Tables S2 and S3).

\section{Interrelationships of Light Responses of Photosynthesis, Stomatal Conductance, and Water-Use Efficiency}

$W_{U} E_{i}$ and $W_{U E}$ inst increased rapidly within low range of $I$, mainly driven by the uncoupled rapidity of photosynthetic and stomatal responses (Figures 1, 2 and Tables 4 and 5; Knapp and Smith, 1990; McAusland et al., 2016). In this study, both $C_{3}$ and 
$\mathrm{C}_{4}$ species showed 100-fold higher initial increase rate of $A_{\mathrm{n}}(\alpha)$ than that of $g_{\mathrm{s}}\left(\alpha_{0}\right)$ (Tables 2 and 3 ). The rapid initial increase of $\mathrm{WUE}_{\mathrm{i}}$ and $\mathrm{WUE}_{\text {inst }}-$ characterized by $\alpha_{1}$ and $\alpha_{2}$, respectivelyoccurred at low $g_{s}$ (and at low $I$ ), when small increase in $g_{\mathrm{s}}$ exerted the greatest impacts on $A_{\mathrm{n}}$ and $T_{\mathrm{r}}$ (Hetherington and Woodward, 2003). The occurrence of the greatest $A_{\mathrm{n}}$ and $T_{\mathrm{r}}$ increase at low $g_{\mathrm{s}}$ also determined that $\alpha_{1}$ would be much higher than $\alpha_{2}$ for a given species (Figure 2 and Tables 4 and 5).

With the increasing $I$ (from 0 to $\sim 800 \mu \mathrm{mol} \mathrm{m}^{-2} \mathrm{~s}^{-1}$ ), faster photosynthesis response than stomatal response led to the decline of intercellular $\mathrm{CO}_{2}$ concentration $\left(C_{\mathrm{i}}\right)$ (Supplementary Figure S1; McAusland et al., 2016), causing further opening of stomatal pores (Mott, 1988) which allowed for diffusion of ambient $\mathrm{CO}_{2}$ into the leaf (Hetherington and Woodward, 2003). Further increase of $g_{\mathrm{s}}$-beyond the low $g_{\mathrm{s}}$ range-led to minimal increase of $A_{\mathrm{n}}$ and $T_{\mathrm{r}}$ (Hetherington and Woodward, 2003), such that $W_{U E}$ and $W U E_{i n s t}$ flattened quickly after reaching the $\mathrm{WUE}_{\mathrm{i}-\max }$ and $\mathrm{WUE}_{\text {inst-max }}$ (Figure 2). Further increase of $I$ beyond $I_{\mathrm{i}-\text { sat }}$ and $I_{\text {inst-sat }}$ led to a decrease in $\mathrm{WUE}_{\mathrm{i}}$ and $\mathrm{WUE}_{\text {inst }}$. To reach $A_{\text {nmax }}$, both soybean and grain amaranth would have to show a decrease of $\mathrm{WUE}_{\mathrm{i}}$ (or $\mathrm{WUE}_{\mathrm{inst}}$ ) from $\mathrm{WUE}_{\mathrm{i}-\max }$ (or $\mathrm{WUE}_{\text {inst-max }}$ ) (Figures 1, 2).

\section{Differential Light Responses of Water-Use Efficiency Between $\mathrm{C}_{3}$ and $\mathrm{C}_{4}$ Species}

The observation-modeling intercomparison in this study highlighted the differential single-peaked $W_{U} E_{i}-I$ and WUE $_{\text {inst }}-I$ responses-besides differential $A_{\mathrm{n}}-I$ and $g_{\mathrm{s}}-I$ responses-between $\mathrm{C}_{3}$ and $\mathrm{C}_{4}$ species (Figure 2 and Tables 4 and 5). $\mathrm{C}_{4}$ species (grain amaranth) showed higher $\mathrm{WUE}_{\mathrm{i}}$ and $W_{U E} E_{\text {inst }}$ than $C_{3}$ species (soybean), suggesting its better leaf-scale optimization of carbon uptake versus water loss than $\mathrm{C}_{3}$ species (Figures 1, 2 and Tables 2, 4, and 5). This may be due to higher photosynthetic capacity and rapidity of stomatal response $\left(\alpha_{0}\right)$ in $\mathrm{C}_{4}$ species under changing irradiance conditions (Figure 1 and Tables 2 and 3), which facilitate relatively closer coupling between $A_{\mathrm{n}}$ and $g_{\mathrm{s}}$ in $\mathrm{C}_{4}$ species than $\mathrm{C}_{3}$ species (McAusland et al., 2016).

Moreover, this study identifies greater interspecific difference in $W_{U E} E_{\text {inst }}$ than that in $W_{U E}$-at high $I$ range when $W E_{i}$ and WUE inst flatten (Figure 2 and Tables 4 and 5). $C_{3}$ species (soybean) showed larger discrepancy between its $\mathrm{WUE}_{\mathrm{i}}-\mathrm{I}$ and WUE inst $-I$ responses than that of $\mathrm{C}_{4}$ species (grain amaranth). This may be due to differential water use strategies between $\mathrm{C}_{3}$ and $\mathrm{C}_{4}$ species $-\mathrm{C}_{4}$ species holds smaller $T_{\mathrm{r}}$ change per unit of $g_{s}$ change in relative to $C_{3}$ species (Knapp, 1993). These results quantitatively demonstrate that the differential $\mathrm{WUE}_{\mathrm{i}}-$ $I$ responses between $\mathrm{C}_{3}$ and $\mathrm{C}_{4}$ species would not necessarily mirror their differential $W_{U E} E_{\text {inst }}-I$ responses (Figure 2).

These results support previous studies reporting that water conservation-in terms of high WUE-is an important consequence of the $\mathrm{C}_{4}$ photosynthetic pathway (besides high carbon gain rate) at different scales including single leaf, whole plant, and even whole communities (Ludlow and Wilson, 1972), 
contributing to the success of $\mathrm{C}_{4}$ species in high irradiance environments (Pearcy and Ehleringer, 1984; Knapp, 1993).

\section{Model Significance}

By providing (1) analytical models characterizing the singlepeaked light responses of $\mathrm{WUE}_{\mathrm{i}}$ and $\mathrm{WUE}_{\text {inst }}$ and (2) key quantitative traits defining $\mathrm{WUE}_{\mathrm{i}}-I$ and $\mathrm{WUE}_{\text {inst }}-I$ response differences between $C_{3}$ and $C_{4}$ species, this study provides a practical and robust modeling approach-in a form potentially applicable to WUE-I models at whole-plant and/or ecosystem scale. In particular, the key quantitative traits-the initial increase rates of $\mathrm{WUE}_{\mathrm{i}}\left(\alpha_{1}\right)$ and $\mathrm{WUE}_{\text {inst }}\left(\alpha_{2}\right)$ besides that of $A_{\mathrm{n}}(\alpha)$ and $g_{\mathrm{s}}\left(\alpha_{0}\right)$, the maximum $\mathrm{WUE}_{\mathrm{i}}\left(\mathrm{WUE}_{\mathrm{i}-\max }\right)$ and $\mathrm{WUE}_{\text {inst }}$ (WUE $\left.E_{\text {inst-max }}\right)$ besides that of $A_{\mathrm{n}}\left(A_{\mathrm{n} \max }\right)$ and $g_{\mathrm{s}}\left(g_{\mathrm{s}-\max }\right)$, and the corresponding saturation irradiances-will directly help physiologists and modelers investigate the interrelationships among photosynthesis, stomatal behavior, and WUE under changing irradiance conditions.

Meanwhile, the above quantitative traits allow for easier and more extensive evaluation of light-intensity consequences on carbon and water relations among different species and/or PFTs. Such quantitative information, gathered on a wider range of species and/or PFTs, could allow (1) a deeper understanding of interspecific variation in light response strategies (Knapp, 1993; Hetherington and Woodward, 2003; McAusland et al., 2016), and (2) a realistic representation of adaptive WUE- $I$ response differences among PFTs into ecosystem modeling.

The explicit models developed in this study can be viewed as an initial step toward filling the gap between investigating the trends of interspecific variation in short-term leaf-scale WUE- $I$ responses and translating the variation into improved process representation in models of plant and ecosystem scales. The findings in this study remain to be validated (1) with species of different growth form and PFT membership (e.g., slower-growing woody species), which could hold different light response strategies (Knapp and Smith, 1989), (2) with daily and seasonal integrals and/or whole-plant estimates of WUE that sometimes could show a low correlation with short-term leafscale WUE observations (Medrano et al., 2015), and (3) when leaf gas exchange is subjected to compound effects of other climatic conditions in current and future climate change scenarios.

\section{CONCLUSION}

The newly developed models (Eqs. 7 and 10, respectively) allow robust reproduction of the differential single-peaked $W_{U E} E_{-}$ $I$ and $\mathrm{WUE}_{\text {inst }}-I$ trends between $\mathrm{C}_{3}$ and $\mathrm{C}_{4}$ species and easy parameterization of key traits defining the trends $\left(\alpha_{1}, I_{\mathrm{i}-\text { sat }}\right.$, $K_{\mathrm{i}}$ and $\mathrm{WUE}_{\mathrm{i}-\max }, \alpha_{2}, I_{\text {inst-sat }}, K_{\text {inst }}$, and WUE $\left.\mathrm{W}_{\text {inst-max }}\right)$. The models can be employed for fast and accurate assessment of plant $W_{U} E_{i}$ and $W_{U E} E_{\text {inst }}$ responses-besides that of photosynthetic and stomatal responses using a consistent modeling frameworkacross all light-limited, light-saturated, and photoinhibitory light intensities. These findings are useful (1) for breeders screening for ideal genotypes target with maximized photosynthesis capacity and optimized WUE, (2) for plant physiologists quantifying 
intra- and/or inter-specific variation in leaf-scale WUE-I responses, and (3) for modelers working on better representation of the coupling between carbon and water processes under dynamic irradiance conditions.

\section{DATA AVAILABILITY STATEMENT}

The datasets generated for this study are available on request to the corresponding author.

\section{AUTHOR CONTRIBUTIONS}

Z-PY and S-XZ drafted the work. All authors contributed substantially to the completion of this work and critically revised the work. Z-PY, H-JK, and Y-GL secured the funding.

\section{REFERENCES}

Ahrar, M., Doneva, D., Tattini, M., Brunetti, C., Gori, A., Rodeghiero, M., et al. (2017). Phenotypic differences determine drought stress responses in ecotypes of Arundo donax adapted to different environments. J. Exp. Bot. 68, 2439-2451. doi: $10.1093 /$ jxb/erx125

Aranda, I., Pardos, M., Puértolas, J., Jiménez, M. D., and Pardos, J. A. (2007). Water-use efficiency in cork oak (Quercus suber) is modified by the interaction of water and light availabilities. Tree Physiol. 27, 671-677. doi: 10.1093/ treephys/27.5.671

Avola, G., Cavallaro, V., Patanè, C., and Riggi, E. (2008). Gas exchange and photosynthetic water use efficiency in response to light, $\mathrm{CO} 2$ concentration and temperature in Vicia faba. J. Plant Physiol. 165, 796-804. doi: 10.1016/j.jplph. 2007.09.004

Baly, E. C. (1935). The kinetics of photosynthesis. Philos. R. Soc. Lond. B 117, 218-239. doi: 10.1098/rspa.1935.0083

Bota, J., Tomás, M., Flexas, J., Medrano, H., and Escalona, J. M. (2016). Differences among grapevine cultivars in their stomatal behavior and water use efficiency under progressive water stress. Agrcult. Water Manage. 164, 91-99. doi: 10. 1016/j.agwat.2015.07.016

Buckley, T. N., and Mott, K. A. (2013). Modelling stomatal conductance in response to environmental factors. Plant Cell Environ. 36, 1691-1699. doi: $10.1111 /$ pce. 12140

Buckley, T. N., Mott, K. A., and Farquhar, G. D. (2003). A hydromechanical and biochemical model of stomatal conductance. Plant Cell Environ. 26, 1767-1785. doi: 10.1046/j.1365-3040.2003.01094.x

Chen, X., Liu, W. Y., Song, L., Li, S., Wu, C. S., and Lu, H. Z. (2016). Adaptation of epiphytic bryophytes in the understorey attributing to the correlations and trade-offs between functional traits. J. Bryol. 38, 110-117. doi: 10.1080/ 03736687.2015.1120370

De Kauwe, M. G., Zhou, S. X., Medlyn, B. E., Pitman, A. J., Wang, Y. P., Duursma, R. A., et al. (2015). Do land surface models need to include differential plant species responses to drought? Examining model predictions across a mesicxeric gradient in Europe. Biogeosciences 12, 7503-7518. doi: 10.5194/bg-127503-2015

Dewar, R. O. (2002). The Ball-Berry-Leuning and Tardieu-Davies stomatal models: synthesis and extension within a spatially aggregated picture of guard cell function. Plant Cell Environ. 25, 1383-1398. doi: 10.1046/j.1365-3040.2002. 00909.x

dos Santos, J. U. M., de Carvalho, G. J. F., and Fearnside, P. M. (2013). Measuring the impact of flooding on Amazonian trees: photosynthetic response models for ten species flooded by hydroelectric dams. Trees 27, 193-210. doi: 10.1016/ j.agrformet.2012.09.005

Dudley, S. A. (1996). Differing selection on plant physiological traits in response to environmental water availability: a test of adaptive hypotheses. Evolution 50, 92-102. doi: 10.1111/j.1558-5646.1996.tb04475.x

\section{FUNDING}

This research was supported by the National Natural Science Foundation of China (Grant Nos. 31560069 and 31960054), the National Key Research and Development Program of China (Grant No. 2016 YFD 03001008), the Key Science and Technology Innovation Team Project of Wenzhou City (Grant No. C20150008), and the National Natural Science Foundation of China (Grant Nos. 31860045 and 31500583).

\section{SUPPLEMENTARY MATERIAL}

The Supplementary Material for this article can be found online at: https://www.frontiersin.org/articles/10.3389/fpls.2020.00374/ full\#supplementary-material

Duursma, R. A., Payton, P., Bange, M. P., Broughton, K. J., Smith, R. A., Medlyn, B. E., et al. (2013). Near-optimal response of instantaneous transpiration efficiency to vapour pressure deficit, temperature and [CO2] in cotton (Gossypium hirsutum L.). Agr. Forest Meteorol. 168, 168-176. doi: 10.1016/j. agrformet.2012.09.005

Eamus, D., Huete, A., and Yu, Q. (2016). Vegetation Dynamics: A Synthesis of Plant Ecophysiology, Remote Sensing and MODELLINg. Cambridge: Cambridge University Press, 331-333.

Egea, G., Verhoef, A., and Vidale, P. L. (2011). Towards an improved and more flexible representation of water stress in coupled photosynthesis-stomatal conductance models. Agr. Forest Meteorol. 151, 1370-1384. doi: 10.1016/j. agrformet.2011.05.019

Fischer, R. A., and Turner, N. C. (1978). Plant productivity in the arid and semiarid zones. Annu. Rev. Plant Biol. 29, 277-317. doi: 10.1146/annurev.pp.29.060178. 001425

Flexas, J., Niinemets, U., Gallé, A., Barbour, M. M., Centritto, M., Diaz-Espejo, A., et al. (2013). Diffusional conductances to CO2 as a target for increasing photosynthesis and photosynthetic water-use efficiency. Photosyn. Res. 117, 45-59. doi: 10.1007/s11120-013-9844-z

Gilbert, M. E., Zwieniecki, M. A., and Holbrook, N. M. (2011). Independent variation in photosynthetic capacity as stomatal conductance leads to differences in intrinsic water use efficiency in 11 soybean genotypes before and during mild drought. J. Exp. Bot. 62, 2875-2887. doi: 10.1093/jxb/erq461

Gomes, F. P., Oliva, M. A., Mielke, M. S., Almeida, A. A. F., and Leite, H. G. (2006). Photosynthetic irradiance-response in leaves of dwarf coconut palm (Cocos nucifera L. 'nana'. Araceae): comparison of three models. Sci. Hortic. 109, 101-105. doi: 10.1016/j.scienta.2006.02.030

Hetherington, A. M., and Woodward, F. I. (2003). The role of stomata in sensing and driving environmental change. Nature 424, 901-908. doi: 10.1038/ nature 01843

Knapp, A. K. (1993). Gas exchange dynamics in C3 and C4 grasses: consequence of differences in stomatal conductance. Ecology 74, 113-123. doi: 10.2307/ 1939506

Knapp, A. K., and Smith, W. K. (1987). Stomatal and photosynthetic responses during sun/shade transitions in subalpine plants: influence on water use efficiency. Oecologia 74, 62-67. doi: 10.1007/BF00377346

Knapp, A. K., and Smith, W. K. (1989). Influence of growth form and water relations on stomatal and photosynthetic responses to variable sunlight in subalpine plants. Ecology 70, 1069-1082. doi: 10.2307/1941376

Knapp, A. K., and Smith, W. K. (1990). Stomatal and photosynthetic responses to variable sunlight. Physiol. Plant 78, 160-165. doi: 10.1111/j.1399-3054.1990. tb08731.x

Köhler, I. H., Macdonald, A. J., and Schnyder, H. (2016). Last-century increases in intrinsic water-use efficiency of grassland communities have occurred over a wide range of vegetation composition, nutrient inputs, and soil PH. Plant Physiol. 170, 881-890. doi: 10.1104/pp.15.01472 
Linares, J. C., and Camarero, J. J. (2012). From pattern to process: linking intrinsic water-use efficiency to drought-induced forest decline. Glob. Change Biol. 18, 1000-1015. doi: 10.1111/j.1365-2486.2011.02566.x

Ludlow, M. M., and Wilson, G. L. (1972). Photosynthesis of tropical pasture plants. IV. Basis and consequences of differences between grasses and legumes. Aust. J. Biol. Sci. 25, 1133-1145. doi: 10.1071/BI9721133

McAusland, L., Vialet-Chabrand, S., Davey, P., Baker, N. R., Brendel, O., and Lawson, T. (2016). Effects of kinetics of light-induced stomatal responses on photosynthesis and water-use efficiency. New Phytol. 211, 1209-1220. doi: 10. 1111/nph. 14000

Medlyn, B. E., De Kauwe, M., Lin, Y. S., Knauer, J., Duursma, R. A., Williams, C. A., et al. (2017). How do leaf and ecosystem measures of water-use efficiency compare? New Phytol. 216, 758-770. doi: 10.1111/nph.14626

Medrano, H., Tomás, M., Martorell, S., Flexas, J., Hernández, E., Rosselló, J., et al. (2015). From leaf to whole-plant water use efficiency (WUE) in complex canopies: limitations of leaf WUE as a selection target. Crop J. 3, 220-228. doi: 10.1016/j.cj.2015.04.002

Mott, K. A. (1988). Do stomata respond to CO2 concentrations other than intercellular? Plant Physiol. 86, 200-203. doi: 10.1104/pp.86.1.200

Pearcy, R. W., and Ehleringer, J. (1984). Comparative ecophysiology of C3 and C4 plants. Plant Cell Environ. 7, 1-13. doi: 10.1111/j.1365-3040.1984.tb01 194.x

Sinclair, T. R., Tanner, C. B., and Bennett, J. M. (1984). Water-use efficiency in crop production. Bioscience 34, 36-40. doi: 10.2307/1309424

Smith, W. K., Knapp, A. K., and Reiners, W. A. (1989). Penumbral effects on sunlight penetration in plant communities. Ecology 70, 1603-1609. doi: 10. 2307/1938093

Song, L., Zhang, Y. J., Chen, X., Li, S., Lu, H. Z., Wu, C. S., et al. (2015). Water relations and gas exchange of fan bryophytes and their adaptations to microhabitats in an Asian subtropical montane cloud forest. J. Plant Res. 128, 573-584. doi: 10.1007/s10265-015-0721-Z

Thornley, J. H. M. (1976). Mathematical Models in Plant Physiology. London: Academic Press, 86-110.

von Caemmerer, S., and Farquhar, G. D. (1981). Some relationships between the biochemistry of photosynthesis and the gas exchange of leaves. Planta 153, 376-387. doi: 10.1007/BF00384257

Wargent, J. J., Elfadly, E. M., Moore, J. P., and Paul, N. D. (2011). Increased exposure to UV-B radiation during early development leads to enhanced photoprotection and improved long-term performance in Lactuca sativa. Plant Cell Environ. 34, 1401-1413. doi: 10.1111/j.1365-3040.2011.02342.x

Webster, R. J., Driever, S. M., Kromdijk, J., McGrath, J., Leakey, A. D. B., Siebke, K., et al. (2016). High C3 photosynthetic capacity and high intrinsic water use efficiency underlies the high productivity of the bioenergy grass Arundo donax. Sci. Rep. 6:20694. doi: 10.1038/srep20694

Xu, Z. F., Hu, T. X., and Zhang, Y. B. (2012a). Effects of experimental warming on phenology, growth and gas exchange of treeline birch (Betula utilis) saplings. Eastern Tibetan Plateau, China. Eur. J. Forest Res. 131, 811-819. doi: 10.1007/ s10342-011-0554-9

Xu, Z. F., Yin, H. J., Xiong, P., Wan, C., and Liu, Q. (2012b). Short-term responses of Picea asperata seedlings of different ages grown in two contrasting forest ecosystems to experimental warming. Environ. Exp. Bot. 77, 1-11. doi: 10.1016/ j.envexpbot.2011.10.011

Ye, Z. P. (2007). A new model for relationship between irradiance and the rate of photosynthesis in Oryza sativa. Photosynthetica 45, 637-640. doi: 10.1007/ s11099-007-0110-5

Ye, Z. P., Suggett, J. D., Robakowski, P., and Kang, H. J. (2013). A mechanistic model for the photosynthesis-light response based on the photosynthetic electron transport of PS II in C3 and C4 species. New Phytol. 152, 1251-1262. doi: 10.1111/nph.12242

Ye, Z. P., and Yu, Q. (2008). A coupled model of stomatal conductance and photosynthesis for winter wheat. Photosynthetica 46, 637-640. doi: 10.1007/ s11099-008-0110-0

Zhou, S., Medlyn, B., Sabaté, S., Sperlich, D., and Prentice, I. C. (2014). Short-term water stress impacts on stomatal, mesophyll and biochemical limitations to photosynthesis differ consistently among tree species from contrasting climates. Tree Physiol. 34, 1035-1046. doi: 10.1093/treephys/tpu072

Zhou, S.-X., Medlyn, B. E., and Prentice, I. C. (2016). Long-term water stress leads to acclimation of drought sensitivity of photosynthetic capacity in xeric but not riparian Eucalyptus species. Ann. Bot. 117, 133-144. doi: 10.1093/aob/mcv161

Zhou, S.-X., Prentice, I. C., and Medly, B. E. (2019). Bridging drought experiment and modelling: representing the differential sensitivities of leaf gas exchange to drought. Front. Plant Sci. 9:1965. doi: 10.3389/fpls.2018.01965

Conflict of Interest: The authors declare that the research was conducted in the absence of any commercial or financial relationships that could be construed as a potential conflict of interest.

Copyright (c) 2020 Ye, Ling, Yu, Duan, Kang, Huang, Duan, Chen, Liu and Zhou. This is an open-access article distributed under the terms of the Creative Commons Attribution License (CC BY). The use, distribution or reproduction in other forums is permitted, provided the original author(s) and the copyright owner(s) are credited and that the original publication in this journal is cited, in accordance with accepted academic practice. No use, distribution or reproduction is permitted which does not comply with these terms. 